\title{
Serviço social e formação permanente: possibilidades de superação de cotidianos de alienação
}

\author{
Priscila Fernanda Gonçalves Cardoso \\ https://orcid.org/0000-0002-3524-7623
}

\author{
Heloise Helena Pereira Nunes ${ }^{3}$ \\ https://orcid.org/0000-0002-7269-3892
}

\author{
Terezinha de Fátima Rodrigues ${ }^{2}$ \\ https://orcid.org/0000-0002-8639-7509
}

\author{
${ }^{1}$ Universidade Federal de São Paulo, Departamento de Políticas Públicas e Saúde Coletiva, Programa de Pós Graduação em Serviço Social \\ e Políticas Sociais, Santos, SP, Brasil \\ ${ }^{2}$ Universidade Federal de São Paulo, Departamento de Políticas Públicas e Saúde Coletiva, Programa de Pós-graduação em Serviço Social \\ e Políticas Sociais, Santos, SP, Brasil \\ ${ }^{3}$ Universidade Federal de São Paulo, Programa de Pós-graduação em Serviço Social e Políticas Sociais, Santos, SP, Brasil
}

\section{Serviço social e formação permanente: possibilidades de superação de cotidianos de alienação}

Resumo: O presente artigo apresenta a importância da formação permanente para o serviço social como possibilidade de contribuição para o trabalho profissional numa perspectiva crítica e de afirmação de nosso projeto ético-político. Para tanto, realiza uma discussão acerca da educação na sociedade de classes e o sentido da formação permanente em uma direção contra-hegemônica aos interesses do capital, apresentando uma reflexão sobre seu papel numa perspectiva emancipatória. Retoma os princípios da Política de Educação Permanente do Conjunto Conselho Federal de Serviço Social (CFESS), Conselhos Regionais de Serviço Social (CRESS) (2012), apontando os desafios e possibilidades presentes na efetivação desta política e na construção de espaços democráticos de formação após a graduação, ressaltando sua importância, aqui compreendida sob dois aspectos: a necessária suspensão da cotidianidade para o retorno a esta, de maneira a contribuir criticamente com ações alinhadas ao projeto ético político profissional e, sua potência enquanto estratégia na manutenção da hegemonia de nosso projeto profissional e de formação.

Palavras-chave: Educação. Formação Permanente. Serviço Social. Projeto Ético-político.

\section{Social work and ongoing training: possibilities of overcoming alienating routines}

Abstract: This article presents the importance of ongoing training for social workers as a possibility of contributing to professional work from a critical perspective and affirmation of a specific ethical-political project. The study discusses education in class society and the meaning of ongoing education in a counter-hegemonic direction to the interests of capital, presenting a reflection on the education's role in an emancipatory way. The article resumes the principles of the Ongoing Education Policy of the Federal Council of Social Work (CFESS) of Regional Councils of Social Service (CRESS) (2012). Also, it points out the challenges and opportunities in the implementation of this policy and construction of democratic spaces of graduate qualifications, emphasizing the importance of ongoing training regarding two aspects. The first is the necessary suspension of the life routine, so one can contribute to the daily life, when returning, through actions aligned with a professional political, ethical project. Second, the potential for ongoing training as a strategy to maintain the hegemony of a professional and education project.

Keywords: Education. Ongoing Training. Social Service. Ethical-Political Project.

Recebido em 30.06.20019. Aprovado em 17.09.2019. Revisado em 13.11.2019.

C O(s) Autor(es). 2020 Acesso Aberto Esta obra está licenciada sob os termos da Licença Creative Commons Atribuição-NãoComercial 4.0 Internacional (https://creativecommons.org/licenses/by-nc/4.0/deed.pt_BR), que permite copiar, distribuir e reproduzir em qualquer meio, bem como adaptar, transformar e criar a partir deste material, desde que para fins não comerciais e que você forneça o devido crédito aos autores e a fonte, insira um link para a Licença Creative Commons e indique se mudanças foram feitas. 


\section{Introdução}

A formação permanente tem se colocado para as/os trabalhadores de uma forma imperiosa, principalmente a partir do final dos anos 1990, em diante, em um contexto de reestruturação produtiva e novos processos fabris.

Há uma dupla dimensão que marca a discussão sobre a formação permanente, demonstrando a contradição posta na sociedade burguesa de qualificação/capacitação de trabalhadores. Inicialmente, a qualificação de quadros de recursos humanos na ótica do mercado de trabalho, o que traz em si, questões vinculadas às exigências do/a trabalhador/a se qualificar para se tornar "competitivo/a" e "mais atraente" quanto a requisitos de sua inserção no mercado de trabalho, com forte presença do arcabouço instrumental, com as técnicas e ferramentas para responder às demandas colocadas em seu trabalho cotidiano. Por outro lado, a perspectiva de formação em uma dimensão de avanços no sentido de conhecimentos e crítica deste cotidiano, possibilitando construir práticas em uma direção social vinculada aos interesses da classe na qual se insere, no caso, a classe trabalhadora. É nesse contexto que nossa reflexão se coloca: as possibilidades da formação e nelas, a formação permanente que amplie cotidianos de alienação, presentes na ordem desumanizadora do capital.

Consideramos fundamental a formação permanente para assistentes sociais em uma concepção de superação de processos alienantes e alienadores que se colocam nos espaços das práticas sociais na sociabilidade do capital. Destarte, debruçamo-nos neste artigo, a realizar uma reflexão crítica, a partir de revisão bibliográfica, sobre a formação permanente e sua importância para o trabalho profissional, tendo como referência a discussão de educação numa perspectiva emancipatória e sua relação com o projeto profissional e de formação hegemônico no serviço social nos últimos 40 anos.

Nossa análise reforça a importância da formação permanente e a perspectiva política deste debate na profissão que avança em termos de construção de uma política de formação permanente para a categoria profissional, por meio da Associação Brasileira de Ensino e Pesquisa em Serviço Social (ABEPSS) e do Conjunto Conselho Federal de Serviço Social (CFESS)/Conselhos Regionais de Serviço Social (CRESS).

Dividimos nossa reflexão em duas partes e tecemos algumas considerações finais. Na primeira parte, apresentamos elementos que nos possibilitam pensar a educação em uma perspectiva emancipatória, baseadas centralmente nos escritos de Mészaros e Frigotto; na segunda parte, articulamos esta reflexão com o debate da formação permanente como possibilidade de suspensão de uma cotidianidade que revela práticas, muitas vezes assentadas na reprodução mecânica e acrítica dos processos sociais, tendo como principais referências os estudos de Heller, Iamamoto e a Política de Educação Permanente do CFESS/CRESS e ABEPSS.

Nas conclusões, buscamos realizar uma síntese dos elementos anteriormente expostos e apontar alguns desafios a serem pensados na efetivação desta política e na construção efetiva de espaços permanentes de formação após o processo de graduação ${ }^{1}$.

\section{A educação em uma perspectiva emancipatória ${ }^{2}$ e o serviço social}

Para pensarmos a educação em um processo contra-hegemônico à lógica do capital, faz-se necessário entender a central articulação entre trabalho e educação. Conforme Marx (1985), trabalho é a mediação homem natureza no sentido da satisfação de necessidades humanas, atividade orientada a um fim para produzir valores de uso. Com isto, o trabalho é "uma condição de existência do homem, independente de todas as formas de sociedade, eterna necessidade natural de mediação do metabolismo entre homem e natureza e, portanto, da vida humana”. (MARX, 1985, p. 50).

Nessa mediação homem-natureza tem-se a instituição de vários complexos sociais assentados nas formas de interação com a natureza, balizados pela transmissão de conhecimentos, pela linguagem, pela cultura. Em uma perspectiva ontológica, tais elementos são considerados riqueza humana. Atos carregados de significados, e especificamente no que se refere à educação, trata-se do "desenvolvimento de condições físicas, mentais, afetivas, estéticas e lúdicas do ser humano (condições omnilateriais) capazes de ampliar a capacidade de trabalho na produção dos valores de uso em geral" (FRIGOTTO, 2010, p. 34). Na produção destes valores, fundamental é a perspectiva de não mercantilização, pois, conforme Frigotto (idem, ibidem) "quando isso ocorre, agride-se elementarmente a própria condição humana".

Alçada à condição de mercadoria, a educação, reproduz interesses antagônicos, assentados na lógica da reprodução do capital; nos dizeres de Mészaros (2008, p. 35), uma educação institucionalizada que, especialmente nos últimos 150 anos, serviu ao propósito de interesses do capital em fornecer conhecimentos e pessoal "necessário à máquina produtiva em expansão do sistema do capital, como também gerar e transmitir um quadro de valores que legitima os interesses dominantes". 
Ainda, refletindo a partir de Meszáros,

O que é que aprendemos de uma forma ou de outra? Será que a aprendizagem conduz à autorrealização dos indivíduos como indivíduos socialmente ricos humanamente (nas palavras de Marx) ou ela está a serviço da perpetuação, consciente ou não, da ordem social alienante e definitivamente incontrolável do capital (2008, p. 47).

Tendo como fundamentos a perspectiva contraditória presente na sociedade onde as relações sociais são históricas, reconhecemos o forte peso das internalizações no contexto educacional formal que implica a adesão a valores burgueses, vinculados à reprodução do capital que se capilariza em um modo de ser e viver em uma ordem social alienante. Ainda, a forma como este trabalho se consolida nos marcos dos processos de produção e reprodução do capital, assentado na lógica da reificação da mercadoria e alienação que implica o não reconhecimento do fruto de seu trabalho, uma lógica assentada na exploração do trabalho, colocando ao trabalhador exigências e requisitos para sua inserção no mercado de trabalho de forma cada vez mais competitiva.

A educação nesta lógica, fortemente direcionada aos interesses das classes dominantes implica na "capacitação deste trabalhador", de uma forma de autorresponsabilização para se tornar competitivo para este mercado e se assenta na formalização de processos de preparação para o mercado. Educação que tem por fim "habilitá-los técnica, social e ideologicamente para o trabalho. Trata-se de subordinar a função social da educação de forma controlada para responder às demandas do capital" (FRIGOTTO, 2010, p. 29).

Porém, na dimensão de contradição dos processos sociais não podemos pensar a educação somente sob este prisma, ainda que nos marcos da sociedade do capital, centralmente essa é a direção no campo da escolarização da classe trabalhadora.

Há que se pensar que a educação não se limita à escolarização formal para o trabalho, mas está presente no conjunto de relações sociais nos contextos históricos dos indivíduos sociais. E, fundamentalmente, concebêla como possibilitadora de processos de superação da alienação presente no cotidiano, como ato político de ampliação das possibilidades de consciência do real, e com isto, como alavanca para processos de mudança social, a partir da reflexão crítica do real. Uma educação em uma perspectiva emancipatória ${ }^{3}$, onde sujeitos sociais se transformam em agentes políticos que pensam e agem na transformação do mundo.

A formação e nelas, a formação profissional vinculada fortemente aos processos educativos tem papel fundamental, ainda que no horizonte civilizacional tenha seus limites, pois se insere na dinâmica da reprodução social.

Apoiadas em tal leitura, ao pensarmos a formação na área de serviço social, compreendemos que a perspectiva de um projeto de formação acadêmico-profissional balizado nas Diretrizes Curriculares da ABEPSS (1996) e uma política de formação permanente avalizada pelos órgãos da categoria profissional de assistentes sociais, no caso, o Conjunto CFESS/CRESS e a ABEPSS implica uma direção social importante no sentido de uma educação em uma perspectiva emancipatória que tem como função "transformar o trabalhador em um agente político, que pensa, que age, e que usa a palavra como arma para transformar o mundo" (JINKINGS apud MESZÁROS, 2008, p. 14).

Tal perspectiva é fruto de um processo de contrução coletiva no interior da profissão e na sua relação com outros segmentos da sociedade, na sua vinculação às lutas da classe trabalhadora. Vale lembrar, no entanto, que esta nem sempre foi a perspectiva hegemônica no serviço social, pelo contrário. A assunção de um ethos emancipatório (que direciona/orienta a formação e o trabalho profissional) data de menos de quatro décadas, tendo sua primeira expressão no currículo mínimo de 1982 e no Código de ética de 1986. É nesse momento que realizamos uma inflexão do conservadorismo à uma perspectiva emancipatória ${ }^{4}$. Para Iamamoto,

[...] nas três últimas décadas, construímos coletivamente um patrimônio sociopolítico e profissional que atribui uma face peculiar ao Serviço Social brasileiro no cenário da América Latina e Caribe e no circuito mundial do Serviço Social. O núcleo desse patrimônio é compreensão da história a partir das classes sociais e suas lutas, da centralidade do trabalho e dos trabalhadores. Ele foi alimentado teoricamente pela tradição marxista - no diálogo com outras matrizes analíticas - e politicamente pela aproximação das forças vivas que movem a história; as lutas e movimentos sociais. (2014, p. 613, grifo do autor).

Essa é a marca das Diretrizes Curriculares da ABEPSS, que constrói uma proposta que tem como princípios, o rigor teórico, histórico e metodológico da realidade social e da profissão, com a necessária apreensão das questões que perpassam o trabalho profissional assentada em uma perspectiva crítica e de compreensão da realidade social como totalidade (ASSOCIAÇÃO BRASILEIRA DE ENSINO E PESQUISA EM SERVIÇO SOCIAL, 1996). Considerando essa dimensão, reforça-se os necessários processos continuados de estudos que não se findam após determinado ciclo formativo. Abre-se para uma perspectiva de formação permanente tendo clara a direção social da profissão, em seus marcos vinculados ao projeto ético político profissional. 
Podemos afirmar que a formação acadêmico-profissional hoje explicita e contribui na manutenção da hegemonia do projeto ético-político, formando profissionais em uma perspectiva crítica, vinculado à defesa dos direitos e a participação na construção de uma sociedade sem opressões. Uma formação sólida, calcada em pressupostos da tradição marxista, que proporciona bases reflexivas ao/a futuro/a profissional, preparando-o/ a para sua ação como um/a profissional crítico/a, reflexivo/a e interventivo/a.

E, após esta formação, como manter a coerência com estes fundamentos no exercício do trabalho profissional? Terá o cotidiano do trabalho profissional espaço para a reflexão sobre o próprio trabalho possibilitando um exercício profissional alinhado com tal formação?

\section{O cotidiano profissional e a formação permanente no serviço social}

Conforme trabalhado anteriormente, compreendemos a educação como um possível instrumento no fortalecimento do ser social na busca de respostas às necessidades humanas e não aos interesses do mercado, apesar de entender a contradição inserida no processo formativo da classe trabalhadora: requisito na inserção no mercado de trabalho, necessário para a venda da força de trabalho e reprodução da vida.

Essa tem sido a forma como o serviço social vem desenvolvendo nos últimos quase 40 anos o seu projeto de formação profissional: ciente do papel de fortalecimento da formação humana e atento às necessidades sociais e do próprio mercado, não para respondê-las na imediaticidade e acriticidade, mas entendendo o lugar de classe trabalhadora dos/as assistentes sociais. Nas palavras de Iamamoto,

A formação profissional aqui referida não se reduz à oferta de disciplinas que propiciem uma titulação ao Assistente Social para responder a uma condição para sua inserção no mercado de trabalho. Se este é um elemento presente no processo de formação, ele o extrapola: trata-se de preparar cientificamente quadros profissionais capazes de responder às exigências de um projeto profissional coletivamente construído e historicamente situado. (2013, p. 191, grifo do autor).

Estando este/a profissional graduado/a, como lidar com as questões apreendidas no processo de formação acadêmico-profissional de maneira crítica e reflexiva no cotidiano do trabalho profissional?

O cotidiano é o espaço onde a vida de todo homem se produz e reproduz. A vida cotidiana é heterogênea, pois é permeada de diversas atividades, e, também é hierárquica, pois as atividades que a constituem se dão em maior ou menor escala. Na sociedade de classes, o trabalho (em forma de emprego) ganha centralidade na vida do/a trabalhador/a como forma de sobrevivência, assim, todas as outras atividades se colocam subordinadas a ele (HELLER, 2000, p. 18). Dessa forma, o homem não realiza o total das suas potencialidades nas atividades que executa, pois o faz de modo fragmentado.

É no cotidiano que a história acontece, pois é nele que a vida do indivíduo se expressa e também da humanidade, sendo o homem simultaneamente um ser genérico e um ser singular.

O homem, ontologicamente, no entanto, não expressa toda a sua humanidade porque além de ser genérico é um ser singular, e toda a busca na satisfação de necessidades se dá no âmbito singular, sendo que a relação entre essas duas dimensões do homem, no cotidiano, acaba se dando de forma muda e inconsciente; "[...] a estrutura da vida cotidiana está caracterizada basicamente pela muda coexistência de particularidade ${ }^{5}$ e genericidade." (HELLER, 2000, p. 23).

Quando há uma base de sustentação, um direcionamento ético-político no agir, maior é a aproximação do homem à sua dimensão genérica, pois a ação perde a automaticidade típica do cotidiano. É nesse movimento de consciência e reflexão que o homem se eleva acima do cotidiano através da escolha e da "concentração de todas as nossas forças na execução da escolha (ou decisão) e a vinculação consciente com a situação escolhida e, sobretudo, com suas consequências." (HELLER, 2000, p. 25).

Segundo a autora, a concentração em todas as escolhas e decisões é contraditória com a própria estrutura da cotidianidade, mas é possível escolher consciente e autonomamente uma atividade para focar inteiramente, o que pressupõe compreender sua totalidade.

O meio para essa superação dialética [Aufhebung] parcial ou total da particularidade, para sua decolagem da cotidianidade e sua elevação ao humano-genérico, é a homogeneização. [...] O que significa homogeneização? Significa, por uma lado, que concentramos toda nossa atenção sobre uma única questão $e$ 'suspenderemos' qualquer outra atividade durante a execução da anterior tarefa; e, por outro lado, que empregamos nossa inteira individualidade humana na resolução dessa tarefa. (HELLER, 2000, p. 27). 
A suspensão da cotidianidade é compreendida, portanto como aspecto essencial para um retorno ao cotidiano de forma crítica e reflexiva, visto que vivenciá-lo permanentemente com a inteireza necessária seria quase impossível diante de suas características de imediaticidade e superficialidade. É neste movimento de suspensão do cotidiano, que se inscreve a possibilidade do encontro de nossa humanidade: a elevação do ser humano-singular ao ser humano-genérico (HELLER, 2000).

E quais os caminhos para pensar a suspensão da cotidianidade? Para Heller (2000) e Lukács (1966), há dois importantes espaços de possibilidade de tal suspensão: a arte e a ciência (Lukács tratará ainda do trabalho criador). "As formas de elevação acima da vida cotidiana que produzem objetivações duradouras são a arte e a ciência". (HELLER, 2000, p. 26).

Não entendemos o serviço social como uma ciência e sim como uma área do saber que produz teorias e conhecimento e que, dentre outras possibilidades da suspensão do cotidiano do trabalho profissional, tem como essencial a criação de ações de formação permanente.

A formação enquanto processo contínuo é uma preocupação do serviço social enquanto categoria, que se expressa nos compromissos assumidos nas agendas das entidades (CFESS, CRESS, ABEPSS e Executiva Nacional de Estudantes de Serviço Social - ENESSO), através da promoção de seminários voltados à atuação do/a assistente social em áreas específicas, como educação, saúde, sociojurídica, previdência, assistência social; cursos; eventos; publicações; e outras ações e iniciativas que contemplam o projeto de formação profissional para além da graduação.

Assim como a formação acadêmico-profissional deve estar pautada nas Diretrizes Curriculares, as ações de formação permanente também precisam estar em conssonância com este projeto de formação e a perspectiva ética assumida em nosso Código de Ética (1993). Trata-se de uma concepção de formação que está além dos cursos imediatistas e com foco técnico-instrumental amplamente ofertados. Iniciativas que compreendam a educação para além dos limites do sistema de ensino e da reprodução da lógica do capital. Processos formativos onde a educação é posta como mercadoria, dificilmente superarão a função de qualificação profissional em resposta às demandas do capital.

Processos de formação permanente pautados na compreensão ontológica de educação possibilitam a suspensão do cotidiano e um olhar crítico acerca das transformações societárias e sua relação com o trabalho profissional.

A profissão conta com uma Política Nacional de Formação Permanente do Conjunto CFESS-CRESS (2012) que se materializa como um instrumento da categoria no desafio do fortalecimento da formação na direção do projeto ético-político e na manutenção de sua hegemonia na medida em que entende que:

[...] pensar a educação permanente no Serviço Social pressupõe, portanto, afirmar o projeto profissional, articulando uma dupla dimensão: de um lado, as condições macrossocietárias que estabelecem o terreno sócio-histórico em que se exerce a profissão, seus limites e possibilidades; e, de outro, as respostas de caráter ético-político e técnico-operativo dos/as agentes profissionais a esse contexto, apoiadas nos fundamentos históricos, teóricos e metodológicos do Serviço Social. (CONSELHO FEDERAL DE SERVIÇO SOCIAL, 2012, p. 8).

Tal política aponta estratégias para fortalecer e promover espaços de formação permanente que permitam a discussão acerca da realidade socioeconômica e política, a reflexão sobre questões contemporâneas, o aprofundamento dos posicionamentos políticos do Conjunto CFESS-CRESS, entre outros, através de debates institucionais, divulgação de materiais didáticos, parcerias institucionais, articulações regionais e criação de planos locais, por exemplo.

No entanto, Nascimento e Oliveira (2016) nos recordam que a formação permanente não se limita a Política do conjunto CFESS-CRESS, pois se trata de uma discussão ampla que extrapola os limites da profissão e que:

[...] assim como os diversos interesses em disputa nesta sociedade expressam ideologias e posicionamentos políticos distintos, os termos, conceitos, categorias de análises também podem assumir sentidos antagônicos em disputa na sociedade, principalmente, pelas contradições que a permeiam. (NASCIMENTO; OLIVEIRA, 2016, p. 137).

Diante disso, consideramos a formação permanente como um instrumento necessário para a sustentação da qualidade da intervenção profissional e do compromisso com a classe trabalhadora, pois possibilita o desvelamento da realidade. A Política de Educação Permanente ressalta a relação profunda e permanente entre a formação e o exercício profissional, compreendendo que é uma relação que se retroalimenta de modo 
que qualifique a atuação do/a assistente social e as respostas aos desafios do cotidiano (CONSELHO FEDERAL DE SERVIÇO SOCIAL, 2012).

Em períodos de crise do modo de acumulação capitalista, traços do conservadorismo ganham forças na sociedade e, o serviço social não está à parte disso. Mesmo com uma formação acadêmico-profissional de base crítica, o/a assistente social está em risco de reproduzir aspectos do pensamento conservador na sua atuação, pois a relação estabelecida desde sua gênese com a questão social, coloca para a profissão a contradição da sociedade de classes, ainda que a/o profissional tenha como compromisso a construção de outra forma de sociabilidade, mais justa e igualitária, sua atonomia é relativa.

Diante disso, a Política de Educação Permanente do Conjunto CFESS-CRESS (2012), ao apresentar a compreensão das entidades da categoria no âmbito da formação permanente e traçar objetivos e estratégias que viabilizem processos de formação na contramão da lógica capitalista, se torna um instrumento de defesa do projeto ético-político e da direção social impressa na proposta vigente de formação acadêmico-profíssional do serviço social, necessária principalmente ao considerarmos as reformas neoliberais e as orientações internacionais $^{6}$ para a educação.

A Política de Educação Permanente traz em suas concepções, a crítica à educação no modelo capitalista e da formação permanente nos moldes da empregabilidade, demarcada centralmente pela assunção a determinado cargo/posição no mercado. Reforça a importância destes processos no sentido do aprimoramento profissional em diferentes dimensões tendo como horizonte a melhora na qualidade dos serviços prestados.

Consolidar uma Política Nacional de Educação Permanente no âmbito do Conjunto CFESS-CRESS, voltada para a promoção do aprimoramento intelectual, técnico e político dos/as assistentes sociais, como forma de qualificar o exercício profissional, fortalecendo sua inserção qualificada e crítica no mundo do trabalho; bem como consolidar o projeto ético-político do Serviço Social e potencializar a melhoria dos serviços prestados aos/às usuários/as. (CONSELHO FEDERAL DE SERVIÇO SOCIAL, 2012, p. 45).

Objetivamente, a formação permanente nessa direção é um desafio que deve ser assumido não só pelas entidades da categoria, como pelas/os assistentes sociais individualmente.

[...] embora as condições de trabalho produzam um conjunto de determinações que em alguns contextos tornam difícil à efetivação da política de educação permanente no cotidiano profissional, é relevante provocar espaços de reflexão acerca dos sentidos da formação continuada numa perspectiva crítica, com vistas, a fortalecer o interesse e o comprometimento profissional com as práticas de educação permanente. (NASCIMENTO; OLIVEIRA, 2016, p. 161).

Pautando-se no compromisso expresso no Código de Ética Profissional (1993), com a qualidade dos serviços prestados, é necessário que o/a assistente social reconheça a importância da formação permanente e se insira em processos que permitam a reflexão crítica de seu trabalho, considerando a dimensão da totalidade e que auxiliem na compreensão dos limites e das possibilidades objetivas e subjetivas da atuação profissional.

A formação permanente, portanto, é um espaço possível de suspensão da cotidianidade quando há uma densidade teórica alinhada com os valores e princípios éticos da profissão em uma perspectiva emancipatória, sem deixar, no entanto, de possibilitar a reflexão do trabalho profissional em suas particularidades nos diferentes espaços sócio-ocupacionais nos quais se insere e da construção de respostas a este trabalho.

\section{Considerações finais}

O tensionamento entre a direção construída historicamente pela profissão e os interesses da classe dominante, contrários a este projeto, está constantemente presente na atuação profissional e se intensifica em tempos de crise do capital, avanço do neoliberalismo e radicalização do conservadorismo.

Embora saibamos da inflexão ocorrida da perspectiva conservadora à uma perspectiva emancipatória enquanto direção intelectual e política da categoria dos/as assistentes sociais (expressa no processo de formação e na legislação própria da profíssão que direciona os/as profissionais, bem como no posicionamento de nossas entidades representativas), não devemos nos enganar supondo o conservadorismo extinto dentre as práticas dos/ as profissionais. Esse é um embate permanente e de disputa que ganha novos contornos e significados na atual conjuntura. E aqui, entendemos o importante papel da formação permanente numa perspectiva emancipatória.

O curto período de graduação tem grandes impactos na vida dos/as futuros/as profissionais, porém se trata de uma formação contra-hegemônica à lógica formal, ao pensamento estrutural e conservador que funda- 
mentam o ensino no Brasil, o que faz com que muitos/as estudantes tenham dificuldade de se vincular ao projeto hegemônico da profissão de imediato. Assim, a formação, enquanto um processo permanente e necessário deve ser compreendida na dimensão da contradição, reconhecendo a possibilidade da direção emancipatória dos procesos de educação.

Como nos ensina Freire, somos seres em processo e em contínua possibilidade de transformação. Como pensar então, que um processo de formação acadêmico-profissional nos forma? Há que se dispor a seguir em processos de formação, e para tanto, criar coletivamente as condições para que este processo ocorra.

[...] Formação é permanente porque é indispensável e é indispensável na medida mesma em que estamos inseridos em um mundo que é inacabado e no qual interferimos. O ser humano - inacabado também porque é histórico, e consciente deste inacabamento - descobre que quanto mais interfere no mundo, que ele não fez e já recebe, tanto mais se indaga [...].

Em síntese, uma vez que o homem é inconcluso porque histórico, não 'é', 'está sendo', e uma vez que a realidade que ele toca também não ‘é', 'está sendo', o ato de tocar o mundo é permanente. (FREIRE, 1992, p.45)

Nesse sentido, entendemos como necessário o compromisso do/a profissional com a busca de momentos de continuidade de sua formação, entendendo que esta não se resume ao período da graduação. Há que se dispor a seguir em processos de formação, e para tanto, criar coletivamente as condições para que estes ocorram. Sabemos que o cotidiano profissional muitas vezes "engole" toda a possibilidade de reflexão e crítica, destarte, os espaços de formação permanente, quando concebidos para além da dimensão demandada pelo sistema capitalista, se colocam como meio e estratégia para garantir a apreensão do real, da razão ontológica dos processos e relações sociais na realidade que o/a profissional se insere, possibilitando a suspensão do cotidiano. Dito de outra forma é essencial mantermos espaços de formação permanente se objetivamos a formação de um/a profissional competente, com perfil propositivo, crítico e vinculado à defesa dos valores expressos em nosso projeto profissional.

Pensar tal perfil nos remete a necessária possibilidade de espaços de suspensão da cotidianidade, no qual as/os profissionais possam realizar processos de reflexão e continuidade de apreensão da perspectiva crítico-dialética, calcada no debate denso acerca da educação, para além da graduação. E se, afirmamos acima ser fundamental o compromisso do/a profissional, aqui apontamos o importante e necessário compromisso das universidades e entidades da categoria.

Entendemos que as entidades da categoria têm avançado na oferta de processos formativos aos/às assistentes sociais e o devem seguir fazendo e ampliando. Acreditamos ainda, que neste momento, faz-se necessário pensarmos algumas outras questões: qual o papel da universidade neste processo? Como ampliar a formação permanente no que se refere à oferta de cursos e atividades para além das pósgraduações e, em especial para além dos mestrados e doutorados? Como ampliar a produção de material com o enfoque no debate do cotidiano profissional? Como garantir que todos esses processos formativos reconheçam a contradição que perpassa os processos educativos?

A Política Nacional de Educação Permanente do Con-

Não entendemos o serviço social como uma ciência e sim como uma área do saber que produz teorias e conhecimento e que, dentre outras possibilidades da suspensão do cotidiano do trabalho profissional, tem como essencial a criação de ações de formação permanente. junto CFESS-CRESS (2012) aponta estratégias para a ampliação desses espaços, e é importante destacar que esta deve continuar sendo uma construção coletiva da categoria, envolvendo e ampliando os diferentes espaços políticos e acadêmicos. É necessário que o conjunto de assistentes sociais reconheça e legitime a possibilidade da formação permanente enquanto estratégia de fortalecimento do projeto ético-político, ou seja, o recohecimento e afirmação destes processos formativos como estratégia de defesa e manutenção da atual direção social impressa à profissão cuja hegemonia foi construída historicamente.

Sabemos que a defesa de uma formação acadêmico-profissional e permanente crítica e reflexiva é um desafio quase hercúleo em tempos de mordaças e silenciamentos no ensino. Mas sabemos também que esta profissão é feita de resistências! Acreditamos que processos educativos em uma perspectiva emancipatória são instrumentos para a formação de consciências críticas e reflexivas, que possibilitem a realização de escolhas e ações cotidianas na construção de outra sociabilidade. 
Obviamente, não creditamos à formação permanente a possibilidade de transformação da realidade, em uma visão ingênua e idealista, mas também sabemos que os que erram na análise, tendem a errar na ação, como nos ensina Marx. Que nos qualifiquemos teórica, ética, política e tecnicamente para dar respostas concretas ao cotidiano tão saturado de imediaticidade, acriticidade e espontaneidade. Que possamos construir processos permanentes de formação como espaços de suspensão da cotidianidade para um retorno a este próprio cotidiano com a inteireza e genericidade humana, necessárias para resistência aos interesses do capital.

\section{Referências}

ASSOCIAÇÃO BRASILEIRA DE ENSINO E PESQUISA EM SERVIÇO SOCIAL (ABEPSS). Lei de Diretrizes Curriculares. Diretrizes gerais para o curso de Serviço Social. Com base no Currículo Mínimo aprovado em Assembleia Geral Extraordinária de 8 de novembro de 1996. Rio de Janeiro: 1996. Disponível em http://www.abepss.org.br/arquivos/textos/documento_ 201603311138166377210.pdf Acesso em: 29 jun. 2019.

ASSOCIAÇÃO BRASILEIRA DE ESCOLAS DE SERVIÇO SOCIAL (ABESS); CENTRO DE DOCUMENTAÇÃO E PESQUISA EM POLÍTICAS SOCIAIS E SERVIÇO SOCIAL (CEDEPSS). Proposta básica para o projeto de formação profissional: documento Abess/Cedepss (nov. 1995). Serviço Social \& Sociedade, n. 50. São Paulo: Cortez, 1996.

BOSCHETTI, Ivanete. Expressões do conservadorismo na formação profissional. Serviço Social e Sociedade. São Paulo, n. 124, p. 637651, out./dez. 2015

CARDOSO, P. F. G. 80 anos de formação em Serviço Social: uma trajetória de ruptura com o conservadorismo. Serviço Social \& Sociedade, São Paulo, n. 127, p. 430-455, set./dez. 2016. Disponível em: http://www.scielo.br/scielo.php?script=sci_arttext\&pid=S0101$66282016000300430 \& \operatorname{lng}=$ pt\&nrm=is\&tlng=pt. Acesso em: 29 jun. 2019.

CARDOSO, P. F. G. Ética e Projetos Profissionais: os diferentes caminhos do Serviço Social no Brasil. Campinas: Papel Social, 2013. CONSELHO FEDERAL DE SERVIÇO SOCIAL (CFESS). Politica de Educação Permanente do Conjunto Cfess-Cress. Brasília, 2012. Disponível em: http://cress-sc.org.br/img/paginas/pep.pdf. Acesso em: 29 jun. 2019.

CONSELHO FEDERAL DE SERVIÇO SOCIAL (CFESS). Código de Ética do/a Assistente Social. Lei n. 8862/93. 10. ed. Brasília. Disponível em: http://www.cfess.org.br/arquivos/CEP_CFESS-SITE.pdf. Acesso em: 29 jun. 2019.

FREIRE, Paulo. Tema 2: Prática didático-pedagógica no processo de formação profissional. In: Maria Lúcia Rodrigues (org.). Ensino de Serviço Social: polêmicas. São Paulo: Educ, 1992.

FRIGOTTO, G. Educação e a crise do capitalismo real. 6. ed. São Paulo: Cortez, 2010.

IAMAMOTO, Marilda Vilela. A formação acadêmico-profissional no Serviço Social brasileiro. Serviço Social \& Sociedade, São Paulo, n. 120 , p. $609-639$, out./dez. 2014. Disponível em: http://www.scielo.br/scielo.php?script=sci_arttext\&pid=S0101$66282014000400002 \& \operatorname{lng}=$ pt\&nrm=is\&tlng=pt. Acesso em: 29 jun. 2019.

IAMAMOTO, Marilda Vilela. Renovação e conservadorismo no Serviço Social: ensaios críticos. São Paulo: Cortez, 2013.

HELLER, Agnes. O cotidiano e a história. 6. ed. São Paulo: Paz e Terra, 2000.

LUKÁCS, Georg. I. La Peculiaridad de lo Estético. Tradução: Manuel Sacristán. Barcelona, Espanha: Grijalbo, 1966.

MARX, K. O Capital: crítica da economia política. Tradução: Regis Barbosa; Flávio R. Kothe. São Paulo: Abril Cultural, 1985. Livro 1, v. 1, t. 1. (Os economistas).

MÉSZAROS, I. A educação para além do capital. 2. ed. São Paulo: Boitempo, 2008.

NASCIMENTO, Chrislayne Caroline dos Santos; OLIVEIRA, Carla Montefusco de. Educação Permanente e Serviço Social: Apontamentos sobre a Formação Profissional. Temporalis, Brasília, ano 16, n. 31, p. 133-165, jan./jun. 2016. Disponível em: http:// periodicos.ufes.br/temporalis/article/view/12321. Acesso em: 29 jun. 2019.

REVISTA SERVIÇO SOCIAL E SOCIEDADE, ano V, n. 14. São Paulo: Cortez, 1988.

\section{Notas}

1 Ao processo realizado durante a graduação, referiremo-nos neste artigo como formação acadêmico-profissional.

2 A perspectiva aqui colocada está calcada na tradição marxista a partir da compreensão da emancipação humana, que vai muito além do uso que este termo (não usado como conceito) tem aparecido em debates sobre a educação, como sinônimo de autonomia ou liberdade individual. Cardoso (2013, p. 56) nos apresenta uma síntese da compreensão deste conceito na tradição marxista: “A partir da tradição marxista, emancipação humana é aqui entendida como a possibilidade da inteireza humana, da objetivação de suas potencialidades enquanto gênero humano: a sociabilidade, a universalidade, a consciência e a liberdade. Da "ultrapassagem da autoalienação"; “[...] aquela que permite a absorção do cidadão abstrato pelo homem individual, que faz deste, em sua vida cotidiana, um ser genérico solidário com os seus semelhantes.” (FREDERICO, 2009, p. 99-106). Para Marx: "Toda emancipação constitui uma restituição do mundo humano e das relações humanas ao próprio homem" (MARX apud IASI, 2011, p. 48)".

3 Entendemos que a educação no sentido amplo (ontológico) tem a função de transmitir o conhecimento, patrimônio cultural, construído pela humanidade. Mas no sentido mais restrito, na sociedade de classes, sempre atenderá prioritamente os interesses dominantes. Destarte, compreendemos 
que nesse processo regado de contradições, o que é possível, é o desenvolvimento de atividades educativas de cunho emancipador, mas não a educação em sua totalidade, independente do compromisso do educador/professor. Sendo a educação, uma mediação da sociabilidade capitalista, infelizmente, não é possível uma educação libertadora em sua totalidade (ou num sentido absoluto), mas, sim, intervenções/ações de cunho educativo que defendam a emancipação humana e contribuam com a mobilização dos sujeitos para a superação da sociedade de classes. Nessa perspectiva é que adotamos aqui a noção de uma educação num sentido emancipatório.

4 Sobre esta inflexão e a trajetória histórica da formação acadêmico-profissional em Serviço Social ver Iamamoto (2014), Cardoso (2016), Revista Serviço Social \& Sociedade (1984)e ABESS/CEDEPSS (1996).

5 A tradução para o português tratou o singular como particular (um grave problema conceitual). Para Heller, a discussão é entre a singularidade e generacidade humanas. A elevação do ser singular ao ser humano-genérico. Assim, nas citações utilizadas de Heller, onde se lê particular, leia-se singular.

6 A partir dos anos 1990, recomendações de organismos internacionais como o Fundo Monetário Internacional e o Banco Mundial incentivaram a mercantilização da educação, em especial o ensino superior. Reformas subordinaram a educação aos interesses do mercado através do barateamento do ensino e da expansão de cursos rápidos. No Brasil, isso se expressa na ampliação das ofertas de cursos de graduação em instituições privadas, no financimaneto e na expansão do ensino a distância. De acordo com Boschetti (2015), o Serviço Social foi fortemente afetado por essas medidas, sendo o terceiro curso com maior número de matrículas na modalidade de ensino a distância, aumentando o contigente de profissionais e abrindo espaço para a ampliação de traços do conservadorismo na formação, debate aprofundado pela autora no texto "Expressões do conservadorismo na formação profissional".

\section{Priscila Fernanda Gonçalves Cardoso}

prifgcardoso@gmail.com

Doutora em Serviço Social pela Pontifícia Universidade Católica de São Paulo (PUC/SP)

Professora Associada I - Universidade Federal de São Paulo (UNIFESP)

\section{Terezinha de Fátima Rodrigues}

terezinha.unifesp@gmail.com

Doutora em Serviço Social pela Pontifícia Universidade Católica de São Paulo (PUC/SP)

Professora Adjunta - Universidade Federal de São Paulo (UNIFESP)

UNIFESP

\section{Heloise Helena Pereira Nunes}

heloise.nunes@unifesp.br

Mestranda no Programa de Pós-graduação em Serviço Social e Políticas Sociais na Universidade Federal de São Paulo (UNIFESP)

Assistente Social - UNIFESP

\section{UNIFESP}

Rua Silva Jardim, 136, Vila Mathias

Santos - SP - Brasil

CEP: $11015-020$

\section{Agência financiadora \\ Não se aplica.}

\section{Contribuições das autoras}

Priscila Fernanda Gonçalves Cardoso, Terezinha de Fátima Rodrigues e Heloise Helena Pereira Nunes, contribuíram igualmente na elaboração do manuscrito.

Aprovação por Comitê de Ética e consentimento para participação

Não se aplica.

\author{
Consentimento para publicação \\ Não se aplica.
}

Conflito de interesses

Não há conflito de interesses. 